Revue des patrimoines

\title{
La peinture murale : héritage et renouveau
} ÉDITORIAL

\section{Laurence de Finance et Marie Monfort}

\section{OpenEdition}

Journals

Édition électronique

URL : http://journals.openedition.org/insitu/10812

DOI : 10.4000/insitu. 10812

ISSN : 1630-7305

Éditeur

Ministère de la Culture

Référence électronique

Laurence de Finance et Marie Monfort, "La peinture murale : héritage et renouveau », In Situ [En ligne], 22 | 2013, mis en ligne le 14 novembre 2013, consulté le 22 septembre 2020. URL : http://

journals.openedition.org/insitu/10812 ; DOI : https://doi.org/10.4000/insitu.10812

Ce document a été généré automatiquement le 22 septembre 2020.

\section{(c) (†) $९$}

In Situ Revues des patrimoines est mis à disposition selon les termes de la licence Creative Commons Attribution - Pas d'Utilisation Commerciale - Pas de Modification 4.0 International. 


\title{
La peinture murale : héritage et
}

\section{renouveau}

\author{
ÉDITORIAL
}

\author{
Laurence de Finance et Marie Monfort
}

1 Ce numéro entièrement consacré à la peinture murale en France regroupe les communications des deux Journées d'études organisées par le musée des Monuments français, les 25 et 26 octobre 2011 à la Cité de l'architecture et du patrimoine et des articles témoignant des recherches en cours sur les peintures murales des $\mathrm{XIX}^{\mathrm{e}}$ et $\mathrm{XX}^{\mathrm{e}}$ siècles.

$2 \mathrm{Au}$ cours des journées d'études d'octobre 2011 sont intervenus différents corps de métiers, architectes, restaurateurs, ingénieurs du Laboratoire de recherche des Monuments historiques (LRMH), historiens de l'art et étudiants qui ont exposé avec une grande rigueur scientifique leur recherche, l'avancée de leurs travaux mais aussi leur questionnement. Toutes ces communications une fois assemblées, comme les éléments d'un puzzle, reflètent l'état actuel de la recherche en peinture murale. Ces journées ont permis de positionner le musée des Monuments français comme tête de réseau d'informations sur l'actualité de la recherche et d'envisager la mise en place de réunions pérennes destinées à rassembler, tous les trois ans, tous les acteurs concernés depuis la découverte d'une peinture murale jusqu'à sa sauvegarde (architectes et conservateurs régionaux des Monuments historiques, conservateurs du patrimoine, conservateurs des antiquités et objets d'art, chercheurs spécialisés en peintures murales, restaurateurs, élus, propriétaires, affectataires..). Un appel à contributions lancé dans le cadre de la publication de ce numéro de la revue In Situ a permis de compléter les textes déjà rassemblés pour proposer au lecteur un état complet de la recherche. 
Figure 1

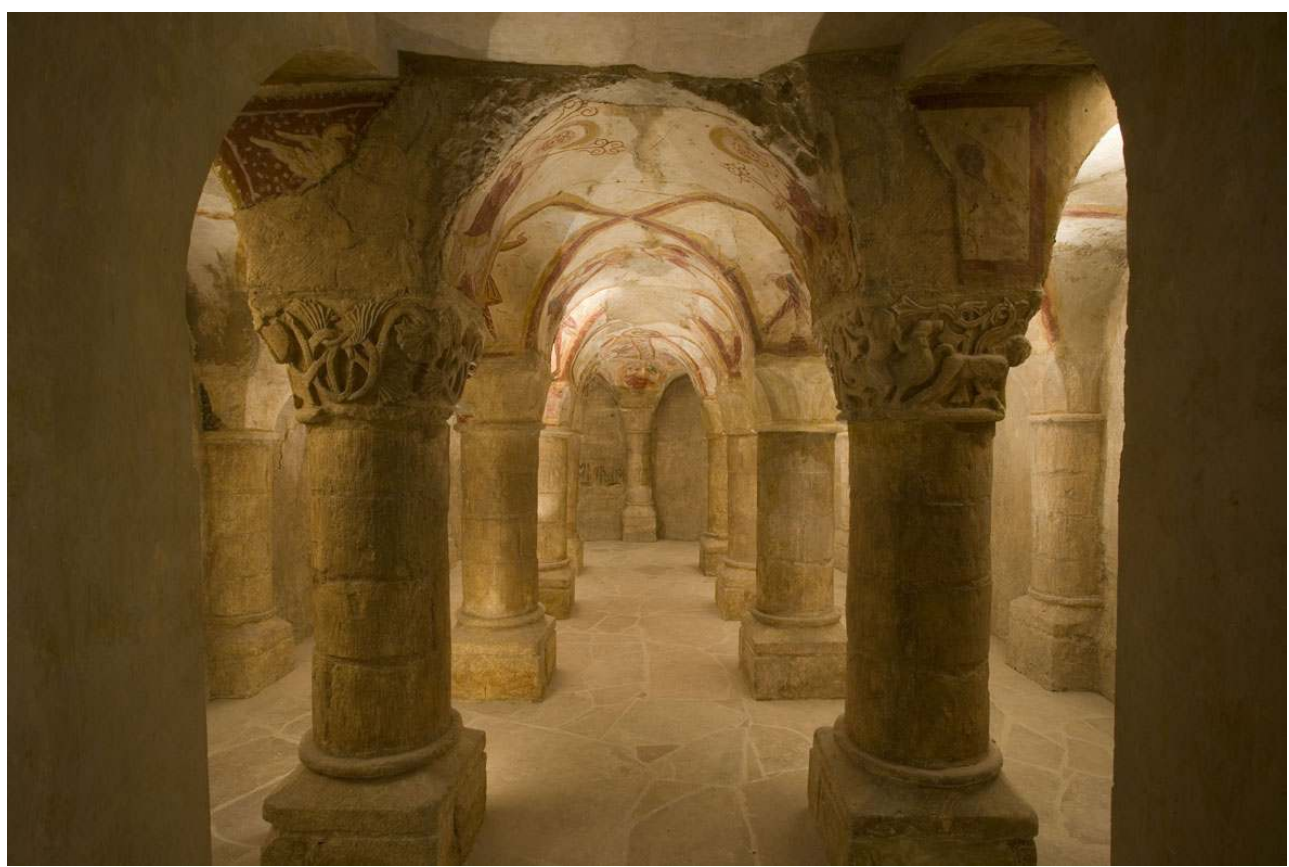

Musée des monuments français, Cité de l'architecture et du patrimoine. Crypte peinte de l'église SaintNicolas de Tavant (Indre et Loire), première moitié du XIIe siècle.

Phot. Borel, N. @ CAPA/MMF.

3 Les articles sont organisés selon trois thématiques qui reprennent la structuration des journées d'études :

4 - L'historique de la création de la collection du musée des Monuments français.

5 - L'importance de ces reproductions pour la conservation des œuvres originales restées en place, en prenant comme exemple la restauration de la voûte de Saint-Savin-surGartempe (Vienne). Ce chantier d'une importance capitale occupa de 2004 à 2008 de nombreux acteurs dont les principaux participèrent à ces journées d'études au cours desquelles furent également présentés des relevés stratigraphiques mis au point par le Centre d'études supérieures de civilisation médiévale (CESCM) qui enrichissent la connaissance de la technique médiévale.

6 - L'état des connaissances avec un point sur l'avancement des inventaires de peintures murales en cours en Auvergne, en Midi-Pyrénées, à leur début en Pays de la Loire, ainsi qu'un rappel des thèses récemment soutenues ou en cours.

7 Il revient au musée des Monuments français de faire le point régulièrement sur l'actualité de la recherche en peinture murale. Pour les journées d'études à venir, d'autres thèmes peuvent être proposés comme axes de réflexion : la peinture murale civile en France au Moyen Âge et à la Renaissance, les liens existant entre peinture monumentale et enluminure, les peintures murales en Europe.

8 Après la période du Moyen Âge et de la Renaissance, la technique de la fresque tomba en sommeil. Seules quelques tentatives évoquées ici, comme celle, malheureuse, de Mottez à Saint-Germain l'Auxerrois à la fin du XIX ${ }^{\mathrm{e}}$ siècle, témoignent d'un intérêt renouvelé.

Par la suite, l'action de Paul Baudoüin, élève de Puvis de Chavanne et premier professeur de fresque à l'école des Beaux-Arts, fut déterminante. Parmi ses élèves, Marthe Flandrin, 
Myrthée Baillon de Wailly, Élisabeth Faure... travaillèrent au relevé du musée des Monuments français, tout en produisant d'abondance pour des églises ou des édifices publics.

10 Cette période est aussi le moment d'un foisonnement d'innovations techniques, d'expérimentations multiples, et d'une grande diffusion de la technique de la fresque.

11 Parmi les peintres fresquistes ayant œuvré au musée des Monuments français, un certain nombre ont fréquenté les ateliers des grands acteurs du renouveau de la fresque dans les années 1920 et 1930.

12 La méconnaissance de cette période de renouveau a souvent engendré des destructions. Récemment, de nombreuses découvertes ont été faites dans ce domaine, grâce au dépouillement de fonds d'archives publiques ou privées, mais aussi lors des chantiers de restauration. Cette période restait en effet méconnue. Espérons que l'étude et la diffusion de ces œuvres permettent une approche renouvelée de ce patrimoine.

\section{AUTEURS}

\section{LAURENCE DE FINANCE}

Conservatrice générale du patrimoine, directrice du Musée des monuments français, Cité de l'architecture et du patrimoine ldefinance@citechaillot.fr

\section{MARIE MONFORT}

Conservatrice du patrimoine, directrice de la Conservation des œuvres d'art religieuses et civiles de la Ville de Paris marie.monfort@paris.fr 